\title{
Odtworzenie czynności rąk po nieodwracalnym uszkodzeniu nerwu promieniowego
}

\section{The restoration of hand functions after irreparable injury of the radial nerve}

\author{
Zbigniew Deskur $^{1 \bowtie}$, Anna Deskur² \\ ${ }^{1}$ Uniwersytet Szczeciński, Wydział Kultury Fizycznej i Promocji Zdrowia, al. Piastów 40b/6, 71-065 Szczecin \\ 2 Pomorski Uniwersytet Medyczny w Szczecinie, Katedra i Klinika Gastroenterologii, ul. Unii Lubelskiej 1, 71-252 Szczecin \\ $\triangle$ zdeskur@onet.pl
}

\begin{abstract}
Introduction: The aim of our study was to evaluate the methods used and results achieved for the restoration of function of the hands in patients with irreparable injury to the radial nerve. Materials and methods: We studied the type and number of methods used for the restoration of mobility function of the hands by tendon transfer of active muscle to affected muscle. Moreover, we implemented rehabilitation treatment in patients with irreparable injury to the radial nerve. Descriptions of the treatment were presented in 6 scientific reports published between 1996 and 2015. The available literature presents the results of the treatment of 129 patients with irreparable injury to the radial nerve. Results: The restoration activities of patients' hand function was most frequently done by tendon transfer, i.e. the pronator
\end{abstract}

teres muscle on the extensor carpi radialis brevis in $100(72.5 \%)$ patients, the palmaris longus muscle on the extensor pollicis longus in $88(68.2 \%)$ patients, and the flexor carpii ulnaris muscle on the extensor digitorum communis in $99(76.7 \%)$ patients. During the pre- and postoperative period rehabilitation treatment played a crucial role in the restoration of patients' hand functions.

Conclusions: All patients regained a complete or almost complete extension of the wrist and fingers. The strength of the hands was generally satisfactory. The dexterity of the hands in the majority of the studied patients was very good or good. Keywords: irreparable injury to the radial nerve; restoration of hand functions; tendon transfer.

\begin{abstract}
ABSTRAKT
Wstęp: Celem pracy była ocena stosowanych metod i osiągniętych wyników odtworzenia czynności rąk u chorych po nieodwracalnym uszkodzeniu nerwu promieniowego.

Materiały i metody: Badano rodzaj i liczbę zastosowanych metod odtwarzania czynności ruchowej rąk przez przeniesienie ścięgien mięśni czynnych na porażone oraz wdrożone leczenie rehabilitacyjne u chorych $\mathrm{z}$ nieodwracalnym uszkodzeniem nerwu promieniowego, które zostały przedstawione w 6 doniesieniach naukowych opublikowanych w latach 1996-2015. W dostępnych pracach przedstawiono wyniki leczenia 129 chorych po nieodwracalnym uszkodzeniu nerwu promieniowego. Wyniki: Czynność rąk przywracano najczęściej przez przeniesienie ścięgna: mięśnia nawrotnego obłego na mięsień prostownik
\end{abstract}

nadgarstka promieniowego długiego u 100 (72,5\%) chorych, mięśnia dłoniowego długiego na mięsień prostownik kciuka długiego u $88(68,2 \%)$ osób oraz mięśnia zginacza nadgarstka łokciowego na mięsień prostownik palców wspólny u 99 (76,7\%) badanych. W okresie przed- i pooperacyjnym w odtworzeniu czynności rąk dużą rolę odegrało leczenie rehabilitacyjne.

Wnioski: U wszystkich chorych osiągnięto prawie pełny lub pełny wyprost nadgarstka i palców. Siła rąk była ogólnie zadowalająca. Sprawność rąk u większości osób była bardzo dobra lub dobra.

Słowa kluczowe: nieodwracalne uszkodzenia nerwu promieniowego; odtworzenie czynności rąk; przeniesienie ścięgien mięśni czynnych na porażone.

\section{WSTĘP}

Zaburzenia czynności rąk mogą powstać po pourazowym uszkodzeniu nerwu promieniowego. Niekiedy po operacyjnej rekonstrukcji nerwu z zastosowaniem nowoczesnych metod mikrochirurgii i transplantologii nie można osiągnąć powrotu czynności nerwu.

Niedostateczna czynność nerwu potwierdzona elektromiografią po odpowiednio długim czasie uważana może być za nieodwracalną. W tej sytuacji odtworzenie czynności rąk można osiągnąć poprzez przeniesienie ścięgien mięśni czynnych na porażone. W nieodwracalnym uszkodzeniu nerwu promieniowego odtworzenia wymagają czynności wyprostne stawu promieniowo-nadgarstkowego, kciuka oraz stawów śródręczno-paliczkowych (MCP) palców II-V.

Wielu chirurgów podejmowało się przywracania czynności wyprostu ręki po nieodwracalnym uszkodzeniu nerwu promieniowego. Jako jeden z pierwszych Jones (1921 r.) do odtworzenia czynności ręki użył dwóch zginaczy nadgarstka. Starr (1922 r.) do prostowania kciuka wykorzystał czynność mięśnia nawrotnego obłego (PT), a Scuderi mięśnia zginacza dłoniowego długiego (PL). Do prostowania palców Zachary (1946 r.) 
przeniósł czynność mięśnia zginacza nadgarstka łokciowego (FCU), a Boyes (1962 r.) mięśnia zginacza palców powierzchownego (FDS) oraz mięśnia zginacza nadgarstka promieniowego (FCR). Starr, a później Brand i Tsuge do wyprostu palców użyli mięśnia FCR. Boyes przenosił czynność mięśnia nadgarstka promieniowego na odwodziciel kciuka i mięśnia prostownika kciuka krótkiego (EPB). Po uszkodzeniu przywodzenia kciuka Omer przenosił czynność mięśnia PL na mięsień prostownik kciuka długiego (EPL). Obecnie po nieodwracalnym uszkodzeniu nerwu promieniowego w odtworzeniu czynności rąk stosuje się różne metody leczenia (ryc. 1). W przywróceniu czynności ruchowej rąk bardzo dużą rolę odgrywa rehabilitacja. Ustalenie jednolitego, najlepszego postępowania utrudnia zbyt mała liczba doniesień na ten temat oraz przedstawianie wielu rodzajów ocen i wyników [1, 2, 3].
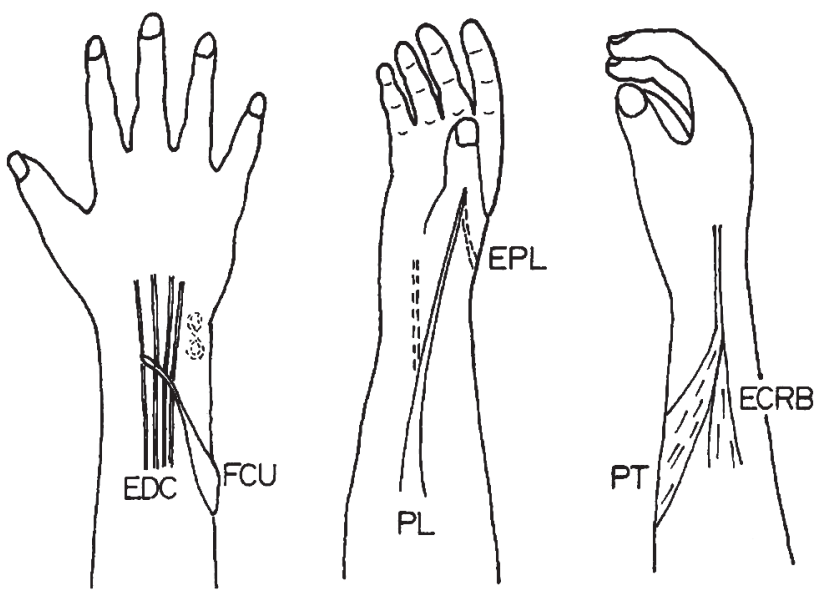

ECRB - mięsień prostownik nadgarstka promieniowy krótki; EDC - mięsień prostownik palców wspólny; EPL - mięsień prostownik kciuka długi; FCU - mięsień zginacz nadgarstka tokciowy; PL - mięsień dłoniowy długi; PT - mięsień nawrotny obły

RYCINA 1. Przeniesienie ścięgien mięśni czynnych na porażone wykonywane u chorych po nieodwracalnym uszkodzeniu nerwu promieniowego [1]

Celem pracy była ocena stosowanych metod odtwarzania czynności rąk i osiągniętych wyników przywracania wyprostu nadgarstka, kciuka i palców II-V oraz siły chwytu rąk u chorych po nieodwracalnym uszkodzeniu nerwu promieniowego.

\section{MATERIAŁY I METODY}

Dokonano retrospektywnej oceny wyników leczenia operacyjnego i rehabilitacyjnego odtwarzania czynności rąk u 129 chorych po nieodwracalnym uszkodzeniu nerwu promieniowego na podstawie doniesień z ogólnie dostępnej literatury naukowej z lat 1996-2015. Kobiet było 14, mężczyzn 115 w wieku 18-64 lat $[4,5,6,7]$ (tab. 1). Uszkodzenie nerwu promieniowego, którego czynności nie można było przywrócić, dotyczyła najczęściej ramienia, splotu ramiennego lub okolicy stawu łokciowego. Okres czasu od uszkodzenia nerwu do leczenia operacyjnego przeniesienia ścięgien wynosił 3-16 lat. Badania czynności rąk od przeniesienia ścięgien dokonano od 6 tyg. do 1 roku. W badaniach określono za pomocą goniometru czynność wyprostną nadgarstka w stawie promieniowo-nadgarstkowym, kciuka i palców II-V w MCP. Siłę chwytu ręki między palcami a dłonią oceniono dynamometrem. W badaniach Deskura [1] do pomiaru siły chwytu rąk użyto urządzenia produkcji Zakładu Mechaniki Precyzyjnej i Sprzętu Medycznego w Pecynie koło Poznania, które było opracowane w Centralnym Ośrodku Techniki Medycznej w Warszawie. Wyniki porównano z ręką zdrową. Obliczenia dokonywano w stosunku do ustawienia ręki w płaszczyźnie przedramienia, tak aby linia biegnąca przez II palec była przedłużeniem linii kości przedramienia.

\section{WYNIKI}

Czynność rąk u 129 chorych przywrócono dzięki odtworzeniu:

1) wyprostu nadgarstka - przeniesienie ścięgna mięśnia PT na mięsień prostownik nadgarstka promieniowy krótki (ECRB) u 100 (77,5\%), FDS na ECRB u 5 (3,9\%), a mięśnia ramienno-promieniowego (BR) na ECRB u 3 (2,3\%) badanych;

2) wyprostu kciuka - przełożenie ścięgna mięśnia PL na EPL u $88(68,2 \%)$ i FDS na EPL u $6(4,66 \%)$ osób;

3) wyprostu palców II-V - przeniesienie ścięgna mięśnia FCU na mięsień prostownik palców wspólny (EDC) u 99 (76,7\%), FCR na EDC u 14 (10,9\%) oraz FDS na EDC u 14 (10,9\%) chorych.

Po przywróceniu wyprostu nadgarstka, kciuka i palców II-V osiągnięto różne wyniki w zależności od sposobu ich określania. Po odtworzeniu wyprostu nadgarstka przez przełożenie ścięgien mięśnia PT na ECRB osiągnięto wynik w granicach $38^{\circ}[7], 31-40^{\circ}$ [1], deficyt wyprostu $7,9 \%$ [3] lub pełny wyprost u 70,7\% leczonych tą metodą chorych [6]. Po przywróceniu wyprostu kciuka przez przeniesienie ścięgna mięśnia PL na EPL osiągnięto średni wyprost $10^{\circ}$ [5], 0-10 ${ }^{\circ}$ stopni [1] oraz pełny wyprost u $22 \%$ [6] leczonych tą metodą chorych. Po odtworzeniu wyprostu palców II-V przez przełożenie FCU na EDC osiągnięto wyprost $0-10^{\circ}[1,4,5,7]$ lub pełny wyprost u 83,3\% [6] wszystkich osób. Po użyciu ścięgna mięśnia FCU założenie tenodezy ósemkowej łokciowo-nadgarstkowej umożliwiło osiągnięcie lepszych wyników [1]. Siła ręki wynosiła 10-20 kg [3, 4, 5, 7] lub 28-50\% badanych miała ocenę bardzo dobrą lub dobrą [1]. Sprawność ręki u większości była bardzo dobra lub dobra.

W odtwarzaniu czynności ruchowej rąk bardzo ważne znaczenie ma leczenie rehabilitacyjne. W okresie przedoperacyjnym u chorych określane były: czynny i bierny zakres ruchów, czucie, siła globalna i chwyty precyzyjne. Sprawdzane były wszystkie zniekształcenia lub blizny. Podczas leczenia usprawniającego starano się znieść wszelkie przykurcze, uzyskać pełny zakres ruchomości w stawach oraz zwiększyć aktywność mięśnia, którego ścięgno będzie przeniesione na ścięgno mięśnia porażonego. Chorzy powinni prowadzić częste, regularne ćwiczenia czynne, czynne z oporem lub mieć zastosowaną elektrostymulację. W leczeniu przykurczów spowodowanych zmianami bliznowatymi stosowano wiele zabiegów fizykoterapii. W okresie pooperacyjnym do 4 tyg. zapobiegano większym napięciom przeniesionego 
TABELA 1. Zestawienie prac odtworzenia czynności rąk przez przeniesienie ścięgien mięśni czynnych na porażone u chorych po nieodwracalnym uszkodzeniu nerwu promieniowego

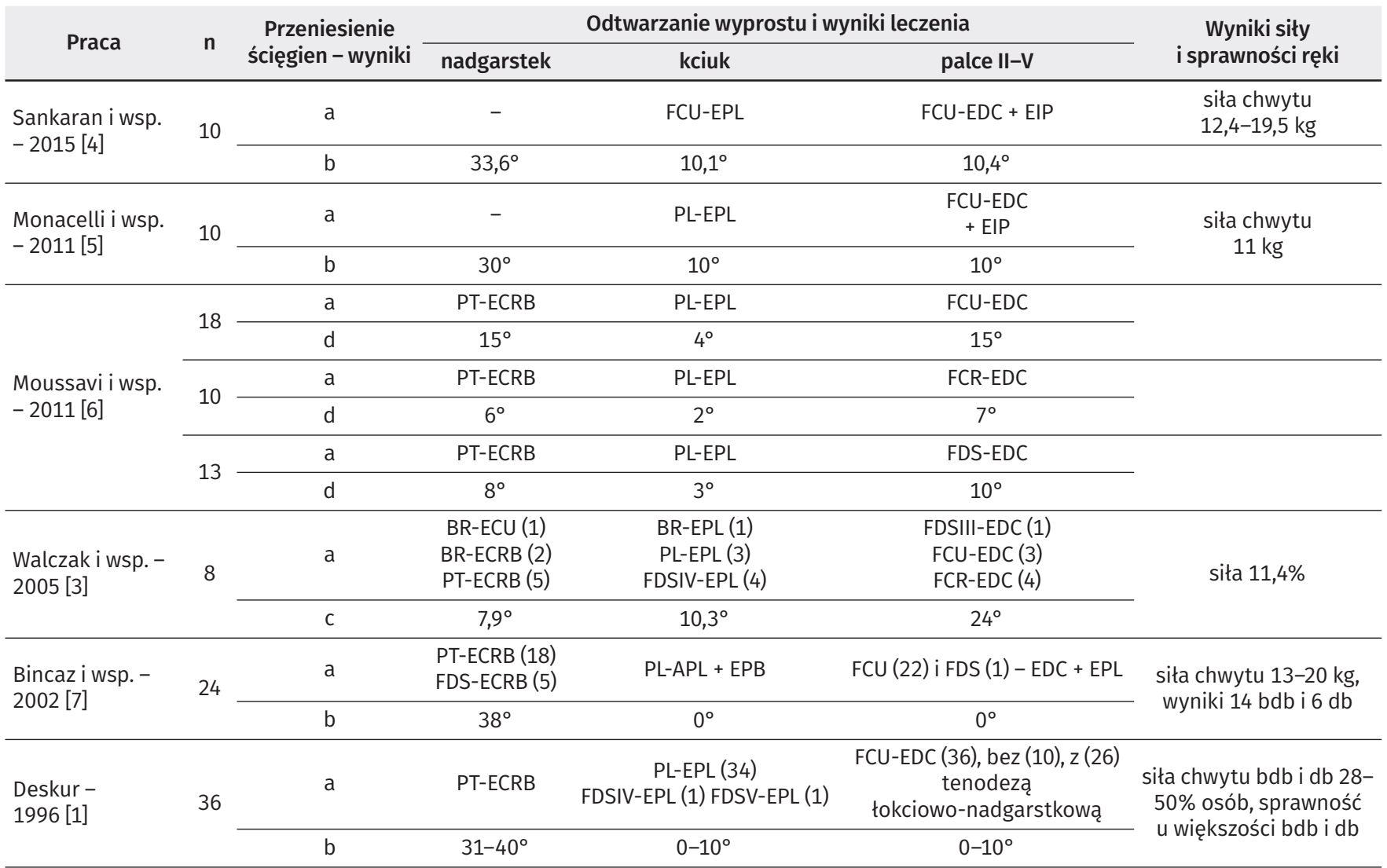

a - przeniesienie ścięgna odpowiedniego mięśnia; b - średnia wartość czynnego wyprostu nadgarstka lub palców w stopniach; c - średnia wartość deficytu wyprostu nadgarstka lub palców w stopniach; d - liczba osób z pełnym wyprostem nadgarstka lub palców. Pomiary wyprostu palców mierzone były w neutralnej pozycji nadgarstka; APL - mięsień odwodziciel kciuka długi; BR - mięsień ramienno-promieniowy; ECRB - mięsień prostownik nadgarstka promieniowy krótki; ECU - mięsień prostownik nadgarstka łokciowy; EDC - mięsień prostownik palców wspólny; EIP - mięsień prostownik wskaziciela własny; EPB - mięsień prostownik kciuka krótki; EPL - mięsień prostownik kciuka długi; FCR - mięsień zginacz nadgarstka promieniowy; FCU - mięsień zginacz nadgarstka łokciowy; FDS - mięsień zginacz palców powierzchowny; PL - mięsień dłoniowy długi; PT - mięsień nawrotny obły

ścięgna. Po unieruchomieniu ręki nadgarstek utrzymywano w wyproście $40^{\circ}$, stawy MCP w pozycji neutralnej, a stawy międzypaliczkowe były wolne, natomiast kciuk utrzymano w odwiedzeniu i wyproście. Aktywność mięśni rozpoczynano od bardzo ostrożnych ćwiczeń izometrycznych w następnym dniu po operacji. Ćwiczenia miały służyć do nauki wykonywania nowego ruchu przez przeniesione ścięgno odpowiedniego mięśnia. Po 4 tyg.od operacji zaczynano ćwiczyć lekkie, częste skurcze przeniesionego mięśnia. Do tych czynności służył aparat dynamiczny. Następnie ostrożnie wprowadzane ćwiczenia czynne, czynne z oporem i koordynacyjne. Po osiągnięciu pozytywnego postępu wdrażano czynności wykonywane w pracy i życiu codziennym $[1,3,5,8]$.

\section{DYSKUSJA}

W nieodwracalnych uszkodzeniach nerwu promieniowego przeniesienie operacyjne ścięgien mięśni czynnych na porażone i prowadzone prawidłowo leczenie rehabilitacyjne pozwala na osiągnięcie dobrych wyników odtworzenia czynności rąk. Przy odtworzeniu wyprostu nadgarstka przeniesienie ścięgna mięśnia PT na ECRB powoduje nie tylko prostowanie nadgarstka, ale i nawracanie przedramienia. Wyprost kciuka często odtwarzany jest przez przeniesienie ścięgna mięśnia dłoniowego długiego na ścięgno mięśnia prostownika kciuka długiego. Przy towarzyszącym uszkodzeniu nerwu łokciowego przeniesienie to może odtworzyć czynność przywiedzenia kciuka. Odtworzenie wyprostu palców często dokonywane jest przez przeniesienie ścięgna mięśnia FCU na ścięgno mięśnia EDC [4]. Mięsień zginacz łokciowy nadgarstka w porównaniu z innymi mięśniami charakteryzuje się duża siłą, ale małą kurczliwością (ok. 4 cm). Użycie mięśnia FCU do wyprostu palców osłabia czynność zgięcia nadgarstka oraz powoduje odchylenie promieniowe ręki [1,3, 9]. Odchylenie to można usunąć poprzez założenie tenodezy łokciowo-nadgarstkowej lub połączenie kości łokciowej z trógraniastą poprzez dalszą część ścięgna mięśnia zginacza łokciowego nadgarstka lub mięśnia prostownika palców [1]. Do wyprostu palców rzadziej używa się przeniesienia ścięgna mięśnia FCR na ścięgno mięśnia EDC $[6,10]$. Przełożenie ścięgna mięśnia FCR w porównaniu z mięśniem FCU powoduje mniejszy deficyt siły zgięcia nadgarstka. Przeniesienie jednoczesne ścięgien mięśni FCR, FCU i PL do odtworzenia wyprostu palców może doprowadzić do nadmiernego wyprostu i ograniczenia zgięcia nadgarstka. Ustawienie ręki w wyproście w stawie 
promieniowo-nadgarstkowym może utrudnić wyprost palców w stawach śródręczno-paliczkowych. Niekiedy do wyprostu palców w stawach śródręczno-paliczkowych stosowane jest ścięgno mięśnia FDS III lub IV przeniesione przez przestrzeń międzykostną $[3,6,7]$. Bezpośredni przebieg przenoszonego ścięgna pozwala na zachowanie siły działającego mięśnia. Zaletą tych mięśni jest ich duża kurczliwość. Wadą tej metody jest powstawanie zrostów. Odtworzenie czynności rąk po wielu latach od uszkodzenia nerwu promieniowego przynosi dobre wyniki $[10,11]$.

Po operacyjnym przeniesieniu ścięgien mięśni czynnych na porażone mogą wystąpić powikłania. Należą do nich: zrosty ścięgien, osłabienie, rozciągnięcie lub zerwanie zespolonego ścięgna.

\section{WNIOSKI}

1. U chorych po nieodwracalnym uszkodzeniu nerwu promieniowego do odtworzenia czynności ruchowej rąk najczęściej stosowano przeniesienie ścięgna mięśnia nawrotnego obłego na ścięgno mięśnia prostownika promieniowego krótkiego nadgarstka, ścięgno mięśnia dłoniowego długiego na ścięgno mięśnia prostownika długiego kciuka oraz ścięgno mięśnia zginacza łokciowego nadgarstka na ścięgno mięśnia prostownika palców.

2. W odtwarzaniu czynności ręki leczenie rehabilitacyjne odgrywa bardzo dużą rolę.

3. Po przeniesieniu czynności mięśni czynnych na porażone w nieodwracalnym uszkodzeniu nerwu promieniowego uzyskano w znacznej większości chorych prawie pełny lub pełny wyprost nadgarstka i palców, znaczny wzrost siły chwytu ręki oraz bardzo dobre i dobre wyniki sprawności rąk.

\section{PIŚMIENNICTWO}

1. Deskur Z. Wartość wybranych metod operacyjnego odtwarzania czynności ręki po nieodwracalnych uszkodzeniach nerwu promieniowego i łokciowego. Szczecin: PAM; 1996.

2. Seiler JG, Desai MJ, Payne SH. Tendon transfers for radial, median, and ulnar nerve palsy. J Am Acad Orthop Surg 2013;21:675-84.

3. Walczak S, Pieniążek M, Pelczar-Pieniążek M, Tabasz M. Zasadność i skuteczność postępowania fizjoterapeutycznego po transferach ścięgien u pacjentów z nieodwracalnym uszkodzeniem nerwu promieniowego. Ortop Traumatol Rehabil 2005;7(2):187-97.

4. Sankaran A, Thora A, Arora S, Dhal A. Single tendon transfer of the flexor carpi ulnaris for high radial nerve injury. J Orthop Surg (Hong Kong) 2015;23(3):345-8.

5. Monacelli G, Spagnoli AM, Rizzo MI, Sorvillo V, Scuderi N. Treatment of persistent radial nerve palsy through "tendon minimal transfer" technique. G Chir 2011;32(1/2):69-72.

6. Moussavi AA, Saied A, Karbalaeikhani A. Outcome of tendon transfer for radial nerve paralysis: comparison of three methods. Indian J Orthop 2011;45:558-62.

7. Bincaz LE, Cherifi $\mathrm{H}$, Alnot JY. Les transferts palliatifs de reanimation de l'extension du poignet et des doigts. A propos de 14 transferts for radial nerve palsies and ten transferts for brachial plexus lesions. Chir Main 2002;21(1):13-22.

8. Kozin SH. Tendon transfers for radial and median nerve palsies. J Hand Ther 2005;18(2):208-15.

9. Moore AM. Tendon transfers for nerve palsies. Washington University School of Medicine. 2015.

10. Martinez-Villen G, Munoz-Marin J, Perez-Barrero P. Are tendon transfers justified in very old hand radial palsies? J Plast Reconstr Aesthet Surg 2012;65(10):293-6.

11. Koulaxouzidis G, Stark GB, Lampert FM. Motorische Ersatzplastik durch Sehnentransposition bei Lahmung des Nerves radialis. Oper Orthop Traumatol 2015;27(1):47-62. 